\title{
Type 2 Diabetes: Local Inflammation and Direct Effect of Bacterial Toxic Components
}

\author{
Judith Miklossy ${ }^{*}, 1$, Ralph Martins ${ }^{2}$, Nune Darbinian ${ }^{3}$, Kamel Khalili $^{3}$ and Patrick L. McGeer ${ }^{1}$ \\ ${ }^{1}$ Kinsmen Laboratory of Neurological Research, University of British Columbia, Vancouver, BC, Canada \\ ${ }^{2}$ Centre of Excellence for Alzheimer's Research and Care, School of Exercise, Biomedical and Health Sciences, Edith \\ Cowan University, The University of Western Australia, Hollywood Private Hospital, Nedlands, WA, Australia \\ ${ }^{3}$ Department of Neuroscience, Center for Neurovirology, Temple University School of Medicine, PA, 19122, USA
}

\begin{abstract}
Objectives: It has been known for almost a century that amyloidosis is frequently associated with chronic bacterial infection. Islet amyloid deposit is characteristic of type 2 diabetes. Periodontal disease, which is predominantly caused by several Gram negative bacteria, is a risk factor for type 2 diabetes. The goal of the study was to explore whether bacteria or their toxic components may play a role in type 2 diabetes.

Material \& Methods: The pancreas in 22 autopsy cases was analyzed for the presence of lipopolysaccharide (LPS), bacterial peptidoglycan (BPG) and local inflammatory processes. Ten of the cases had clinically diagnosed type 2 diabetes, and 12 were age matched controls.

Results: The results of an immunohistochemical analysis showed the presence of LPS and BPG in association with islet amyloid deposits in all the 10 diabetic cases as well as in 3 controls with clinically silent amyloid deposits. Chlamydia pneumoniae and Helicobacter pylori specific antigens were detected in the affected islets in a subset of diabetic patients. Clumps of HLA-DR positive activated macrophages, abundant immunoreactivity to the activated complement components C3d, C4d and C5b-9, the terminal attack complex, and a mild numbers of T4 and particularly of T8 lymphocytes were present in the pancreas of all diabetic cases.

Conclusions: These results suggest that bacteria or their slowly degradable remnants may initiate and sustain chronic inflammation in the pancreas and therefore play a role in the pathogenesis of type 2 diabetes. They also indicate that local immune responses, including activation of the classical complement pathway are important in the pathogenesis of type 2 diabetes. There may also be some involvement of the adaptive immune system. Further investigations are essential since a parallel use of antibacterial and anti-inflammatory drugs may prevent or slow down the disease progression.
\end{abstract}

Keywords: Amylin, Clamydophila, Chlamydia pneumoniae, bacterial peptidoglycan, complement, diabetes, Gram negative bacteria, HLA-DR, Helicobacter pylori, inflammation, LPS, macrophages, spirochetes.

\section{INTRODUCTION}

Type 2 diabetes, non insulin dependent diabetes mellitus (NIDDM), or adult-onset diabetes, is characterized by the progressive degeneration of islet $\beta$-cells of the pancreas resulting in a fall of insulin secretion and decreased insulin action on peripheral tissues. In type 2 diabetes, there is an accumulation of amylin, a 37-amino acid islet amyloid polypeptide (IAPP), in the affected Langerhans islets. It is derived from proamylin, a 89 -amino acid precursor protein [13]. Amylin is produced and secreted, along with insulin, by islet $\beta$-cells. It is related to the calcitonin/calcitonin generelated peptide family, and is involved in homeostatic maintenance [4]. The cause of diabetes type 2 and the mechanisms involved in amyloid formation are not yet known.

Common forms of periodontal disease, which are predominantly caused by Gram negative bacteria, are risk

*Address correspondence to this author at the University of British Columbia, Kinsmen Laboratory of Neurological Research, 2255 Wesbrook Mall, Room 3N6, Vancouver BC, V6T 1Z3, Canada; Tel: 0114179207 4442; E-mail: judithmiklossy@bluewin.ch factors for type 2 diabetes [5-9] and treatment of periodontal infections in diabetics improves glycemic control [6-9].

It has been known for almost a century that amyloidosis is frequently associated with chronic bacterial infections [10, 11]. Lipopolysaccharide (LPS), the toxic product of Gram negative bacteria and bacterial peptidoglycan (BPG), the building block of the cell wall of virtually all prokaryotes, have long been used as models of experimental amyloidosis. LPS and BPG are powerful inflammatory stimulators and are amyloidogenic [10]. Seroprevalence of Chlamydia (Chlamydophila) pneumoniae (C. pneumoniae) [12] and Helicobacter pylori (H. pylori) [13-15] and a significantly high percentage of fluorescent treponemal antibody reaction [16] were observed in diabetic patients compared to controls. The question is raised as to whether bacteria or their toxic products may be involved in type 2 diabetes.

Since bacteria, LPS and BPG are powerful inflammatory stimulators and because inflammation plays an important role in the pathogenesis of several age related degenerative disorders, (e.g. Alzheimer's disease) [17], we expected that local inflammatory processes may also be present in the pancreas in type 2 diabetes. 
Accordingly, the present study was undertaken to analyze whether LPS, BPG and local inflammatory processes are present in association with islet amyloid deposits in 10 patients with type 2 diabetes compared to 12 aged matched controls. Immunohistochemical detection of specific $C$. pneumonae and $H$. pylori antigens was also performed.

\section{MATERIAL \& METHODS}

\section{Autopsy Cases Investigated}

Pancreatic tissue from 22 autopsy cases was analyzed (Table 1). The series included 10 patients with clinically diagnosed type 2 diabetes (Average age: 73, 9 - range 6678 ), including one patient with associated pancreatic cancer (Case 9. Table 1) and 12 age matched controls (Average age: 71, 7 - range 54-86). No diabetes was clinically recorded and no pathological changes were observed by routine pathological examination in the pancreas in the 12 control cases.

In each case samples about $2 \times 1 \times 0.5 \mathrm{~cm}$ large were removed from the pancreas. One was embedded in paraffin and another was frozen in liquid $\mathrm{N}_{2}$ and stored at $-80^{\circ} \mathrm{C}$ until processing. Paraffin sections $(7 \mu \mathrm{m})$ were used for the histochemical analysis and frozen sections (7 or $20 \mu \mathrm{m})$ for both, the histochemical and immunohistochemical analyses. The frozen sections, depending on the antibody utilized, were postfixed with $4 \%$ paraformaldehyde for 10 minutes at room temperature or in acetone for $2-10 \mathrm{~min}$ at $4^{\circ} \mathrm{C}$.

\section{Histochemical and Immunohistochemical Analyses}

Paraffin embedded and 4\% paraformaldehyde fixed frozen sections of the pancreas were stained by haematoxylin and eosin (H\&E). Thioflavin $\mathrm{S}$ and Congo red techniques were used to detect islet amyloid deposits.

The types and dilutions of antibodies used are detailed in Table 2. Two polyclonal rabbit antibodies, one raised against human IAPP 1-37 (Hammersmith, kind gift of Dr. A Clark) and one against rat amylin (Peninsula Laboratories, RGG7323, kind gift of Dr. Bruce Verchere) as well as a monoclonal antibody (clone R10/11, Serotec) raised against a synthetic peptide sequence within IAPP, were used to detect amylin. The sequences recognized by the polyclonal antibodies were verified using membrane arrays of roboti-

Table 1. Summary of the Results

\begin{tabular}{|c|c|c|c|c|c|c|c|c|c|c|c|c|c|c|}
\hline $\mathbf{C N}$ & Age/S & Amyl & LPS & BPG & $\mathrm{C} 3 / 43$ & C3bi & CD20 & CD4 & CD8 & C3d & C4d & C5b-9 & Chl. p & H. pyl \\
\hline \multicolumn{15}{|c|}{ Diabetes Type 2 Cases } \\
\hline 1. & $76 / \mathrm{M}$ & +++ & +++ & +++ & - & - & - & - & - & - & - & - & - & - \\
\hline 2. & $69 / \mathrm{M}$ & +++ & +++ & +++ & - & - & - & - & - & - & - & - & - & - \\
\hline 3. & $79 / \mathrm{F}$ & +++ & +++ & +++ & +++ & +++ & 0 & ++ & +++ & +++ & +++ & +++ & ++ & 0 \\
\hline 4. & $77 / \mathrm{F}$ & +++ & +++ & +++ & +++ & +++ & 0 & ++ & +++ & +++ & +++ & +++ & 0 & 0 \\
\hline 5. & $73 / \mathrm{M}$ & +++ & +++ & +++ & +++ & +++ & 0 & ++ & +++ & +++ & +++ & +++ & ++ & ++ \\
\hline 6. & $73 / \mathrm{F}$ & +++ & +++ & +++ & +++ & +++ & 0 & + & +++ & +++ & +++ & +++ & ++ & 0 \\
\hline 7. & $66 / \mathrm{M}$ & +++ & +++ & +++ & +++ & +++ & - & - & - & - & - & - & - & - \\
\hline 8. & $75 / \mathrm{M}$ & +++ & +++ & +++ & +++ & - & + & ++ & +++ & +++ & +++ & +++ & ++ & ++ \\
\hline $9 . *$ & $73 / \mathrm{F}$ & +++ & +++ & +++ & +++ & +++ & + & ++ & +++ & +++ & +++ & +++ & + & ++ \\
\hline 10. & $78 / \mathrm{M}$ & +++ & +++ & +++ & + & - & - & - & - & - & - & & & \\
\hline \multicolumn{15}{|c|}{ Control Cases } \\
\hline 11. & $78 / \mathrm{F}$ & 0 & 0 & 0 & 0 & 0 & 0 & 0 & 0 & 0 & 0 & 0 & 0 & 0 \\
\hline 12. & $76 / F$ & 0 & 0 & 0 & 0 & 0 & 0 & 0 & 0 & 0 & 0 & 0 & 0 & 0 \\
\hline 13. & $69 / \mathrm{F}$ & 0 & 0 & 0 & - & - & - & - & - & - & - & - & - & - \\
\hline 14. & $60 / \mathrm{M}$ & 0 & 0 & 0 & - & - & - & - & - & - & - & - & - & - \\
\hline 15. & $82 / \mathrm{F}$ & 0 & 0 & 0 & - & - & - & - & - & - & - & - & - & - \\
\hline 16. & $75 / \mathrm{M}$ & 0 & 0 & 0 & - & - & - & - & - & - & - & - & - & - \\
\hline 17. & $86 / \mathrm{M}$ & + & + & + & - & - & - & - & - & - & - & - & - & - \\
\hline 18. & $76 / \mathrm{F}$ & ++ & ++ & ++ & - & - & - & - & - & - & - & - & - & - \\
\hline 19. & $56 / \mathrm{M}$ & 0 & 0 & 0 & - & - & - & - & - & - & - & - & - & - \\
\hline 20. & $68 / \mathrm{F}$ & 0 & 0 & 0 & - & - & - & - & - & - & - & - & - & - \\
\hline 21. & $67 / \mathrm{M}$ & 0 & 0 & 0 & - & - & - & - & - & - & - & - & - & - \\
\hline 22. & $84 / \mathrm{F}$ & ++ & ++ & ++ & + & + & 0 & 0 & + & + & + & + & + & + \\
\hline
\end{tabular}

Abbreviations: $\mathrm{CN}=$ Case number; Age/ $\mathrm{S}=$ Age in year/Sex; Amyl = Islet amyloid deposit as verified by thioflavin S, Congo red and anti-amylin antibodies; LPS = Bacterial lipopolysaccharide; $\mathrm{BPG}=$ Bacterial peptidoglycan; Chl. $\mathrm{p}=$ Chlamydia pneumoniae $; \mathrm{H}$. pyl $=$ Helicobacter pylori $;+=$ mild, $++=$ moderate, $+++=$ severe, $0=$ Absence of immunoreaction; - = Analysis was not perfomed. * = Diabetes type 2 was associated with an adenocarcinoma of the pancreas. 
cally synthesized overlapping peptides [18] covering the amylin sequence. The "Hammersmith" antibody strongly recognized the sequence NFGAILSSTN (amino acids 22-31) of amylin. The RGG-7323 strongly recognized the sequence QRLANFLVHS (amino acids 10-19) which differs from the rat only in the $\mathrm{H}$ to $\mathrm{R}$ of position 18 (not shown). The monoclonal antibody R10/99 (Genetex) is reported by the supplier to recognize an epitope defined by amino acids 29-37.

An extended immunohistochemical analysis was performed using a panel of antibodies to detect LPS, BPG and cellular and humoral immune responses in the pancreas. Two monoclonal and a polyclonal antibody against LPS were utilized. One monoclonal antibody (J5) was raised against the inner core of LPS and the other against lipid A which are highly conserved in Gram negative bacteria. The polyclonal rabbit antibody was made against purified LPS from $E$. coli (Biodesign B30506R) which cross-react with the LPS of other Gram negative bacteria. Immunostaining with the J5 and the polyclonal anti-LPS antibodies was performed on unfixed frozen sections mounted on slides. Immunostaining with the anti-Lipid-A antibody was performed on frozen sections fixed in acetone for $2 \mathrm{~min}$ at $4^{\circ} \mathrm{C}$ and treated with $0.1 \%$ amylase for 3 minutes at $37^{\circ} \mathrm{C}$. $\mathrm{BPG}$ was detected as previously described [19].

Immunohistochermical detection of specific C. pneumoniae and $H$. pylori antigens using pancreas sections fixed with 4\% paraformaldehyde for 5 minutes was also performed in six diabetic and three control cases (Cases 3, 4-6, 8, 9 and $11,12,22$, Table 1). For the detection of $C$. pneumoniae, two species specific monoclonal antibodies, clone RR402 (M 6600, Dako Cytomation) [20, 21] and clone 57/062, 1984-9038, Biogenesis, which do not cross-react with other Chlamydia species and a polyclonal, genus specific antibody (B47829R, Biodesign) which recognizes $C$. pneumoniae, $C$. trachomatis and $C$. psittaci were used. For the detection of $H$. pylori a polyclonal antibody was employed, which was known for its specificity and sensitivity to detect $H$. pylori in infected tissues in gastritis and gastric cancers [22-24].

Anti-human-HLA-DR (Clone C3/43) and anti-C3bi (CD11b or Mac-1, DakoCytomation, M0741) antibody, which recognizes inflammatory cells expressing complement receptor 3 (CR3), were used to detect activated macrophages. Antibodies to sensitive markers of B (CD 20) and T (CD4, CD8) lymphocytes were used to study cellular immune responses and antibodies to the human complement components $\mathrm{C} 3 \mathrm{~d}, \mathrm{C} 4 \mathrm{~d}$, and the membrane attack complex C5b-9 (DAKO, M0777) were used to detect complement activation.

For immunostaining, the avidin-biotin-peroxidase technique was used as described previously in detail [25]. Smears of cultured Escherichia coli and acetone fixed frozen sections of the tonsil of an aged patient, known to contain Gram negative bacteria as part of the oral flora, were used as positive controls for the detection of LPS and BPG. Sections immunostained with normal serum alone were used as controls.

To analyze whether LPS, BPG and islet amylin deposits are localized in the same areas of the diabetic pancreas, serial

Table 2. The Primary Antibodies Employed in the Present Study

\begin{tabular}{|c|c|c|c|c|}
\hline Antigen & Antibody [ref] & Source & Type & Dilution \\
\hline Amylin (a.a. 22-31) & IAPP $1-37$ & (Hammersmith) & Rabbit, IgG & $1: 400$ \\
\hline Amylin (a.a.10-19) & IAPP $1-37$ & (Peninsula RGG7323) & Rabbit, IgG & $1: 100$ \\
\hline Amylin (a.a. 29 -37) & GTX 74673 & GeneTex, Inc. & Mouse IgG & $1: 200$ \\
\hline Bact. peptidoglycan & $7263-1006$ & Biogenesis & Mouse IgG & $1: 500$ \\
\hline E. coli LPS & B30506R & Biodesign & Rabbit antisera & $1: 200$ \\
\hline Anti-coreLPS J5 & $\mathrm{C} 55156 \mathrm{M}$ & Biodesign & Mouse IgG $2 b, \kappa$ & $1: 100$ \\
\hline Lipid A, clone $26-5$ & C61212M & Biodesign & Mouse IgG 2b & $1: 100$ \\
\hline HLA-DP-DQ-DR & $\mathrm{CR} 3 / 43$ & DakoCytomation & culture sn & $1: 200$ \\
\hline CD 20, cloneL26 & B cell & DakoCytomation & culture sn & $1: 200$ \\
\hline $\mathrm{CD} 4$, clone MT310 & T 4 cell & DakoCytomation & culture sn & $1: 200$ \\
\hline CD 8, clone DK25M & T 8 cells & DakoCytomation & culture sn & $1: 200$ \\
\hline C3bi receptor, CD11 & M0741 & DakoCytomation & culture sn & $1: 100$ \\
\hline $\mathrm{C} 3 \mathrm{~d}$ & 2413276 & Janssen & Mouse, IgG & $1: 200$ \\
\hline $\mathrm{C} 4 \mathrm{~d}$ & A213 & Quidel & Mouse, IgG & $1: 200$ \\
\hline C5b9, clone aE11 & M0777 & DakoCytomation & Mouse, IgG & $1: 200$ \\
\hline C. pneumoniae & clone RR402 & DakoCytomation & Mouse IgG & $1: 100$ \\
\hline C. pneumoniae & clone $57 / 062$ & Biogenesis & Mouse, IgG & $1: 100$ \\
\hline Chlamydia genus & B47829R & Biodesign & Rabbit, IgG & $1: 200$ \\
\hline H. pylori & В 0471 & DakoCytomation & Rabbit, IgG & $1: 200$ \\
\hline
\end{tabular}

The source, type and the dilutions are given for each antibody. 
sections spaced 7-14 $\mu \mathrm{m}$ apart were immunostained with antiLPS, anti-BPG and anti-amylin antibodies, respectively. Double immunofluorescent staining to detect overlapping expression of LPS and amylin was also carried out with fluorescence-tagged secondary antibodies as previously described [25]. For this purpose, pancreatic sections with islet amyloid deposits were incubated with a mixture of a polyclonal anti-human amylin (Hammersmith, dil. 1:200) and a monoclonal anti-core LPS J5 antibody (Dil 1:100). A combination of monoclonal anti-amylin (GTX 74673, GeneTex) and rabbit anti-LPS (B30506R, Biodesign) antibodies was also used.

To analyze whether HLA-DR positive macrophages are also associated with islet amyloid deposits pancreas sections of diabetic patients were doubly immunostained using monoclonal anti-HLA-DR (DakoCytomation, Carpinteria, CA, dil. 1:100) and polyclonal anti-amylin (a.a. 22-31, Hammersmith, dil. 1:200) antibodies. The same anti-HLADR antibody was also combined with a polyclonal anti- $C$. pneumoniae antibody (B47829R, Biodesign) to analyze whether this intracellular pathogen may be associated with activated macrophages.

Semiquantitative analysis of amylin, bacterial antigens, inflammatory markers, including complement components C3d, C4d and C5b-9 (Table 1) was performed in all cases. It was based on the severity of the immunoreaction observed in the Langerhans islets and was entered in four grades: absence of immunoreaction - ; mild + ; moderate ++ ; and severe +++ immunoreaction.

\section{Immunoabsorbtion Assay}

Immunoabsorption was used to further test the specificities of the LPS and BPG antibodies. For the antiLPS antibodies, commercially available purified E. coli Serotype 055-B5 LPS (Sigma, L-4524) was used as the antigen. To $50 \mu \mathrm{g}$ of purified LPS, $500 \mu \mathrm{l}$ TRIS and $2.5 \mu \mathrm{l}$ antiLPS antibody (anti-core LPS J5 or polyclonal anti-LPS) were added. In parallel, the same amount of anti-LPS antibody was diluted in $500 \mu \mathrm{l}$ of TRIS. Following overnight rotation of these samples at $4{ }^{\circ} \mathrm{C}$, they were centrifuged at $2300 \mathrm{rpm}$ for 20 minutes. Following filtration $(0.2 \mu \mathrm{m}$ Millipore filter) the supernatants were used for immunostaining of pancreatic sections of patients with type 2 diabetes. Immunoabsorbtion for the anti-BPG antibodies was performed as previously reported [19].

\section{RESULTS}

Amyloid deposits in Langerhans islets (Fig. 1A outlined with arrows) were not easy to recognize on H\&E-stained sections in patients with type 2 diabetes, particularly in cases with less severe alterations. However, they were easily detected by thioflavin S (Fig. 1B) and Congo red (not shown) staining as well as by their amylin immunoreactivity (Fig. 1C). Such islet amyloid deposits were found in the pancreas in all 10 diabetic cases. Islet amyloid deposits of a lesser degree were observed in three of the control cases but were totally absent in the other 9 controls (Table 1). On immunostained sections where the use of primary antibody was omitted were negative (not shown).
A positive immunoreaction in the affected Langerhans islets was obtained with all 3 anti-LPS antibodies (Fig. 1DF) as well as with the anti-BPG antibody (Fig. 1G). Control pancreatic sections, except for the 3 cases with minor amyloid deposits, gave negative staining of the pancreatic islets with LPS (Fig. 1H) and BPG (Fig. 1I).

On serial sections which were immunostained for LPS, BPG and amylin, respectively, LPS, BPG and amylin were all localized in the affected areas of the pancreatic islets. Localization of amylin and LPS in the same areas of the affected islet of a diabetic patient is illustrated in Fig. (1J-K), where a pancreatic section was doubly stained using immunofluorescence with the monoclonal anti-core LPS J5 antibody and the polyclonal anti-amylin (Hammersmith) antibodies. The use of TRITC tagged secondary antibody for the anti-core LPS J5 antibody produced a red LPS fluorescence (Fig. 1J) and the FITC tagged secondary antibody for the polyclonal antiamylin antibody produced a green fluorescence for amylin (Fig. 1K). The orange color on the merged images in Fig. (1L) indicates the overlap of LPS and amylin.

At high magnification at the periphery of homogenous islet amyloid deposits, helically shaped (0.1-0.3 x 10-40 $\mu \mathrm{m})$ coiled filaments (e.g. Fig. $\mathbf{2 A}, \mathbf{C}$ ), sometimes forming rings or globular structures (Fig. 2A, asterisk) as well as, coccoid forms of about $1 \mu \mathrm{m}$ in diameter (Fig. 2B,D), sometimes forming pairs, could be observed. These were seen on thioflavin S-stained and on LPS- and BPG-immunostained sections. LPS positive round or granular structures $(0.3-2 \mu \mathrm{m}$ in diameter) accumulating intracellularly (Fig. 2E) were also observed. In some cases accumulation of LPS and BPG positive structures reminiscent of bacteria were also seen along the pancreatic septae. These helically shaped filamentous (Fig. 2F,G) and small coccoid structures (Fig. 2H) reminiscent of various forms of bacteria were also immunoreactive for $\mathrm{C} 5 \mathrm{~b} 9$, the membrane attack complex which assembles only on viable cell membranes. Fig. (2I) illustrates bacterial structures recognized by anti-core LPS J5 antibody in the tonsil of an aged patient known to be the site of accumulation of Gram negative bacteria and which was used as positive control. Positive $C$. pneumoniae immunoreaction was observed in the affected Langerhans islet (Fig. 3A-C) in 5 of the 6 diabetic cases analyzed (Cases 3, 5, 6, 8, 9 of Table 1). H. pylori were detected in the pancreatic islets (Fig. 3E-G) of three patients with type 2 diabetes (Cases 5, 8, 9 of Table 1). In three diabetic cases $C$. pneumoniae and $H$. pylori were both detected in pancreatic islets (Cases 5, 8, 9 of Table 1). C. pneumoniae was detected intracellularly as a less or more dense granular intracytoplasmic staining (Fig. 3B,C). Similar C. pneumoniae immunoreaction was also seen in atherosclerotic lesions of small sized pancreatic arteries in some diabetic cases (not shown here). On pancreas sections doubly immunostained with HLA-DR and $C$. pneumoniae antibodies, overlapping expression of HLA-DR activated macrophages and the intracellular pathogen $C$. pneumoniae was observed (not shown here).

H. pylori immunostaining appeared as slightly curved rod like $(0.5-1 \times 2-7 \mu \mathrm{m})$ bacillary structures (Fig. 3F,G) observed extracellularly. Pancreas sections of the two control cases without islet amyloid deposit (Cases 11 and 12, Table 


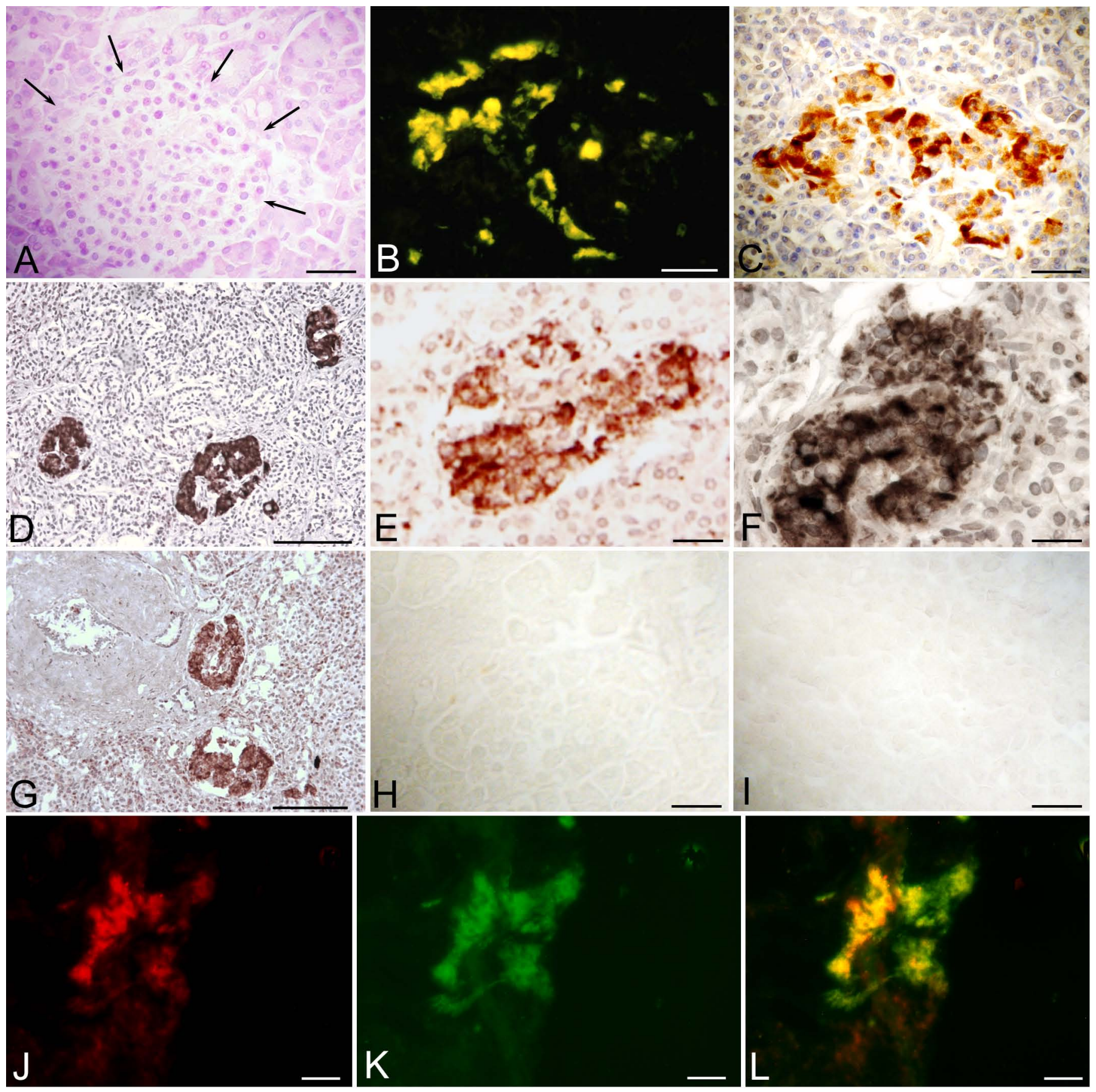

Fig. (1). LPS and bacterial peptidoglycan in the Langerhans islet in type 2 diabetes. (A) In the Langerhans islet outlined by arrows no apparent amyloid deposit is visible on haematoxyline and eosin-stained section in a patient with type 2 diabetes. (B and $\mathbf{C})$ Islet amyloid deposit in a diabetic patient exhibiting green thioflavin $\mathrm{S}$ fluorescence $(\mathbf{B})$ and brown amylin immunoreaction $(\mathbf{C})$ with a rabbit anti-amylin antibody (IAPP 1-37). (D-F) LPS immunoreaction in the Langerhans islets with anti-core LPS J5 (D) anti-Lipid A (E) and polyclonal antiLPS (F) antibodies in a patient with type 2 diabetes. (G) Bacterial peptidoglycan (BPG) in the affected Langerhans islet in a patient with type 2 diabetes. (H and I) LPS or BPG are not detected in the pancreas of a control patient without islet amyloid deposit with anti-core LPS (H) and anti-BPG (I) antibodies. (J,K) Pancreas section of a diabetic patient doubly immunostained with monoclonal anti-core LPS J5 and polyclonal anti-amylin antibodies. The red LPS immune-fluorescence $(\mathbf{J})$ and green amylin fluorescence $(\mathbf{K})$ were both localized in the Langerhans islet. The orange color on the merged captured images (T) shows co-localization of LPS and amylin. Bars in (A-C) $70 \mu \mathrm{m} ;(\mathbf{D})$ and $(\mathbf{G})$ $200 \mu \mathrm{m},(\mathbf{E}, \mathbf{F}, \mathbf{H}, \mathbf{I}) 50 \mu \mathrm{m} ;(\mathbf{J}-\mathbf{L}) 40 \mu \mathrm{m}$.

1) were negative for $C$. pneumoniae and $H$. pylori (Fig. 3D and $\mathbf{3 H}$, respectively). In the third control case with clinically silent islet amyloid deposit $C$. pneumoniae and $H$. pylori were both detected (Case 22, Table 1). The immunoreac- tion for both was mild when compared to that of the diabetic cases. Control sections where immunostaining was performed with the omission of the primary antibody were negative (not shown). 

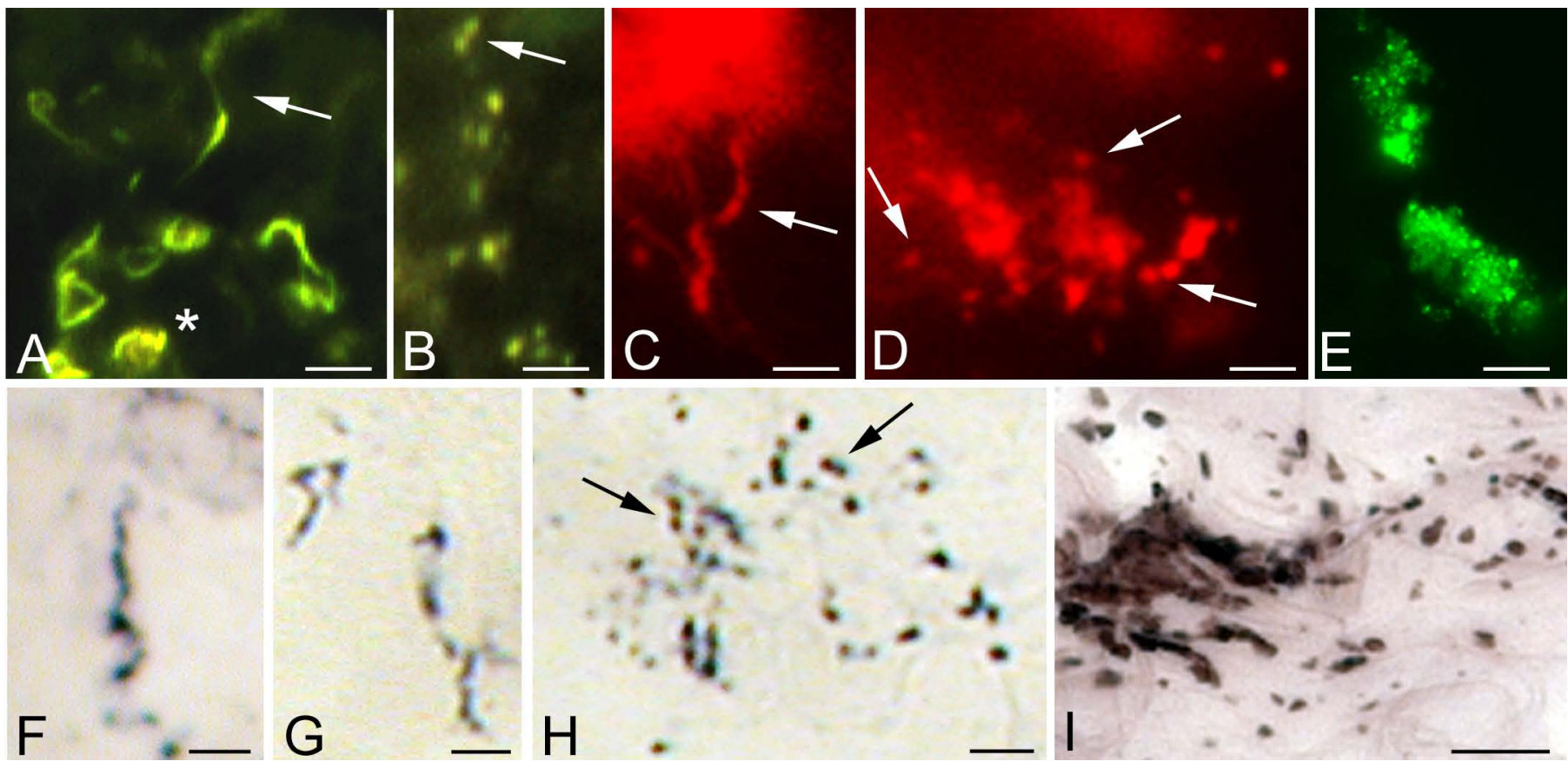

Fig. (2). Thioflavin S and LPS positive structures morphologically compatible with bacteria in type 2 diabetes. (A) Helically shaped filaments (arrow) sometimes forming rings and globular structures (asterisk) exhibiting green thioflavin S fluorescence. (B) Round coccoid structures of about $1 \mu \mathrm{m}$ in diameter sometimes forming pairs (arrow). Thioflavin S technique. (C and D) LPS J5 positive filamentous (C, arrow) and coccoid structures (D, arrows) at the borders of a homogenous LPS immunoreactive mass in the affected islet of a diabetic patient. The TRITC labeled secondary antibody yielded red LPS J5 fluorescence. (E) Finely granular intracellular LPS J5 immunofluorescence in the Langerhans islet of a diabetic patient. (F-H) C5b9 immunoreactive helically shaped $(\mathbf{F}, \mathbf{G})$ and coccoid structures $(\mathbf{H}$, arrows) morphologically compatible with bacteria are observable in the pancreatic islet. For immunostaining a monoclonal antibody to the terminal membrane attack complex (C5b9) was used. (I) LPS immunoreaction in a fibrotic area of the tonsil of an aged patient used as positive control for bacteria. Bars: (A-G) $5 \mu \mathrm{m}$; (I) $8 \mu \mathrm{m}$.

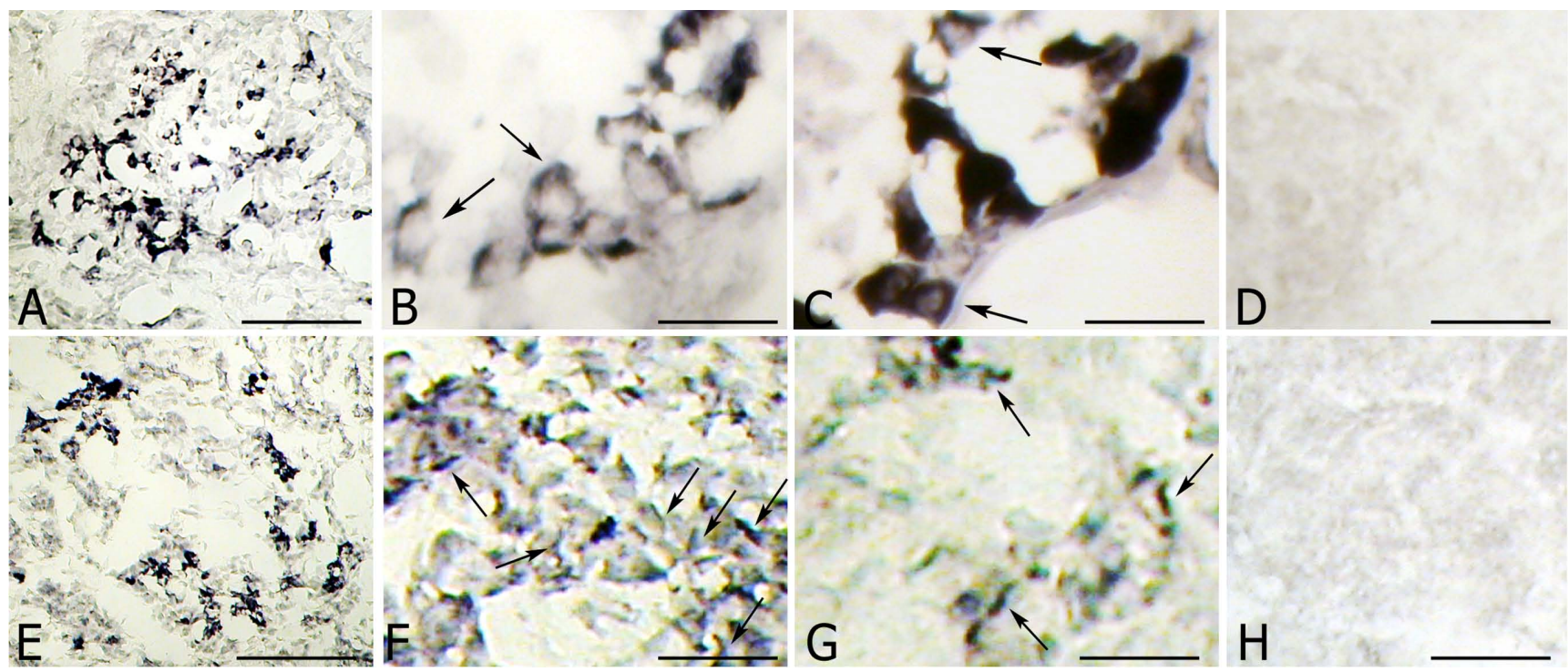

Fig. (3). Chlamydia pneumoniae and Helicobacter pylori in the pancreatic islets in type 2 diabetes. (A-C) C. pneumoniae immunostaining in the Langerhans islet of a patient with type 2 diabetes. At high magnification intracellular C. pneumoniae immunoreaction in the cytoplasm of large cells morphologically compatible with activated macrophages is visible. Arrows point to some cells where the unstained nucleus is better visible. (D) C. pneumoniae is not detected in the Langerhans islets of a control patient without diabetes and without islet amyloid deposit. (E) H. pyloryi immunoreaction in the pancreatic islet of a diabetic patient. (F and G) Extracellularly located $H$. pylori immunoreactive, slightly curved, rod-like bacilli typical of $H$. pylori are seen (arrows). At higher magnification (G) the typical slightly curved appearance is better visible (arrows). (H) H. pylori was not detected in the pancreas of a control patient. Bars in $(\mathbf{A}, \mathbf{D}, \mathbf{E}, \mathbf{H}) 200 \mu \mathrm{m} ;(\mathbf{B}, \mathbf{C})$ $70 \mu \mathrm{m} ;(\mathbf{F}) 20 \mu \mathrm{m} ;(\mathbf{G}) 15 \mu \mathrm{m}$. 


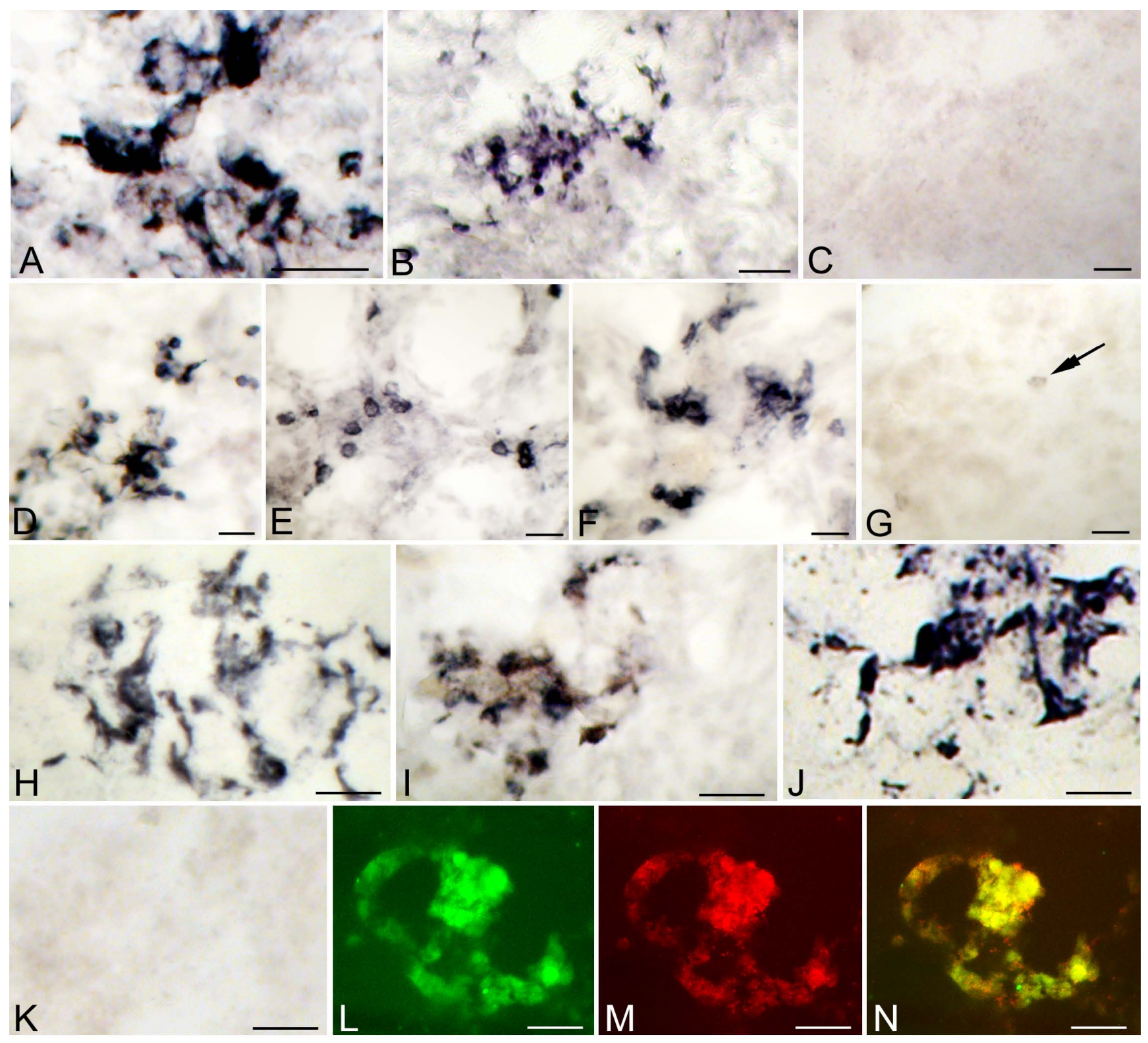

Fig. (4). Local inflammatory processes in the pancreas in type 2 diabetes. (A and B) Clumps of CR3/43 (HLA-DR) (A) and C3bi (B) immunoreactive inflammatory cells in the pancreas of a patient with type 2 diabetes. (C) Pancreas section of a control patient without diabetes stained with anti-HLA-DR antibody. (D,E) Pancreas sections of a diabetic patient immunostained with anti-CD20 (D), CD4 (E) and CD8 (F) antibodies, respectively. (G) Pancreas section of a non-diabetic patient immunostained with anti-CD8 antibody showing only rare CD8 labeled T cells (arrow). (H-J) illustrate abundant immunoreactivity to C3d (H), C4d (I) and C5b9 (J) complement proteins in the pancreas of a patient with type 2 diabetes. (K) Pancreas section of a control patient immunostained with anti-C5b9 antibody. (L-N) Section of the pancreas of a patient with type 2 diabetes doubly immunostained with polyclonal rabbit anti-amylin (green fluorescence) and monoclonal antiHLA-DR (red fluorescence) antibodies. On the merged fluorescent images the yellow color indicates that HLA-DR positive activated macrophages accumulate in areas with islet amyloid deposits. Bars in (A-K) $50 \mu \mathrm{m}$; (L-N) $100 \mu \mathrm{m}$.

A strong inflammatory response was associated with amyloid deposits in the diabetic cases (Fig. 4). Clumps of HLA-DR (Fig. 4A) and C3bi (Fig. 4B) immunoreactive cells surrounded islet amyloid deposits but were absent in control pancreas (Fig. 4C). Only a few CD20 immunoreactive B cells were observed in the diabetic pancreas (Fig. 4D) along with modestly increased numbers of CD 4 (Fig. 4E) immunoreactive cells. The number of the CD 8 (Fig. 4F) positive lymphocytes (Fig. 2G) was the highest. Only scattered
CD 20, CD 4, or CD8 positive lymphocytes, sometimes in relation to blood vessels, were seen in the controls (Fig. 4G).

Abundant immunoreactivity to activated complement proteins was clearly observed in the pancreas of all diabetic cases. This is illustrated for C3d (Fig. 4H), C4d (Fig. 4I) and C5b-9 (Fig. 4J). Such immunoreactivity was associated with islet amyloid deposits, and in some cases was also seen along the loose connective tissue of fine pancreatic septae. Focal HLA-DR positive activated macrophages and C3d, 
C4d and C5b-9 immunoreactivities were also associated with atherosclerotic lesions of pancreatic arteries observed in some diabetic cases. Immunoreactivity for complement proteins was not observed in the Langerhans islets of control cases (Fig. 4K) except in one (Case 22, Table 1) with mild clinically silent amyloid deposits. On doubly immunostained sections amyloid deposition and inflammatory reactions, complement activation (e.g. amylin and HLA-DR illustrated in Fig. (4L-N)) overlapped in affected areas of the Langerhans Islets.

\section{DISCUSSION}

Type 2 diabetes, which accounts for $90-95 \%$ of all diabetic cases, has become a major health concern [26]. Using anti-LPS and anti-BPG antibodies, we demonstrated the presence of these two bacterial toxic components in the affected Langerhans islets of all type 2 diabetic cases analyzed. On doubly immunostained pancreatic sections, LPS and BPG were co-localized with amylin. Amyloid deposit, LPS and BPG immunoreactivity of a mild degree was also observed in the pancreas in three control cases. It is possible that they corresponded to early, subclinical cases of type 2 diabetes. Bacteria, or their toxic products, would be expected to initiate a local inflammatory reaction; however the occurrence of local inflammation in type 2 diabetes is not established. We observed clumps of HLA-DR and C3bi positive macrophages around islet amyloid deposits. Such cells are designed to clean foreign cells such as bacteria and damaged host cells and debris, including extracellular amyloid deposits. Abundant immunoreactivity to the activated complement proteins C3d, C4d and C5b-9 was also present, clearly showing that the classical complement pathway is fully activated in type 2 diabetes. Such results are similar to those observed in Alzheimer's disease [27-29]. These results indicate that local immune responses are involved in the pathogenesis of type 2 diabetes, which would not be surprising, given the presence of LPS a known activator of the macrophage receptor CD14 [30]. Despite the apparent lack of lymphocytic infiltrates on H\&E stained sections of the pancreas in 8 of the 10 type 2 diabetic cases, using sensitive immuno-markers of $\mathrm{B}$ and $\mathrm{T}$ lymphocytes, increased number of CD4, and particularly of CD 8 positive $\mathrm{T}$ cells, were present compared to controls indicating the possibility of a minimal involvement of the adaptive immune system.

The presence of LPS and BPG and observance of C5b-9 positive structures morphologically compatible with bacteria suggest that chronic bacterial infection may be involved in type 2 diabetes. The membrane attack complex only assembles on viable cell membranes eliminating the possibility that C5b-9 immunoreactive bacterial structures may correspond to post mortem bacterial growth. Intracellular C. pneumoniae was observed in the affected islets in 5 of the 6 diabetic cases analyzed and extracellularly located slightly coiled $H$. pylori immunoreactive bacteria were also seen in the affected Langerhans islets in 3 diabetic cases. Simultaneous occurrence of $C$. pneumoniae and $H$. pylori antigens was observed in 3 cases. These results suggest that $C$. pneumoniae and $H$. pylori may be candidate pathogens for type 2 diabetes. Chronic periodontitis is a known risk factor for type 2 diabetes $[5-9,31]$ and the periodontal pathogen $T$. denticola predominated in chronic periodontal lesions of patients with type 2 diabetes compared to controls [31]. We have observed
LPS, BPG and C5b-9 positive helically shaped bacteria morphologically identical to vegetative and atypical forms of spirochetes in several diabetic patients suggesting that spirochetes (including oral and intestinal spirochetes) may also be candidate pathogens for type 2 diabetes. The present results are in harmony with classical observation that the onset of diabetes may occur during or after an acute infection and that the occurrence of diabetes in chronic bacterial infections like tuberculosis, leprosy and syphilis is repeatedly documented.

C. pneumoniae [32-35], H. pylori [36-38] and periodontal pathogens, including $T$. denticola $[39,40]$ and virus infection are also linked to cardiovascular disorders including atherosclerosis indicating that these infectious agents, via haematogen dissemination, may reach and infect various organs distant from the primary site of infection. Some intestinal pathogens (e.g. H. pylori) may also reach the pancreas directly from the gastrointestinal tract. The simultaneous occurrence of $C$. pneumoniae and $H$. pylori and the various types of LPS and BPG positive (coccoid, rod, helically shaped or fusiform) organisms in pancreatic islets of the same diabetic patient suggest that similarly to periodontitis and atherosclerosis concurrent infection by several pathogens may also occur in type 2 diabetes. Improvement of glycemic control was observed after eradication of $H$. pylori infection in diabetic patients which further suggests that early antibiotic and anti-inflammatory treatment may be efficient to prevent or slow down the disease process [41]. That pathogens may evade host defenses and establish chronic or latent infection has received little attention in the past. The outcome of infection is determined by the genetic predisposition of the patient $[42,43]$ and by the virulence and biology of the infecting agent. Environmental factors and nutrition are key determinants of disease expression as well. Bacteria are powerful stimulators of inflammation and are amyloidogenic.

The present results suggest that type 2 diabetes may be caused by inflammatory processes in the pancreas, initiated by invading pathogens or their persisting toxic components (e.g. LPS and BPG) and involving innate and possibly even adaptive immune responses. In the affected pancreas the pathogenic bacteria and/or their toxic components can be observed, along with a host immunological response. The response itself appears to be characteristic of a localized inflammatory process associated with the sites of tissue damage, similar to that e.g. seen in Alzheimer's disease [44-47].

Careful prospective studies are needed. In addition to diagnostic serological tests, and an attempt to cultivate bacteria from the pancreas, in parallel, the detection of specific antigens and genes (e.g. PCR, in situ hybridization) in pancreas of patients with type- 2 diabetes should be done.

In conclusion, the present results indicate that local inflammatory processes and the bacterial toxic components LPS and BPG are present in the affected Langerhans islets in patients with type 2 diabetes. The results also suggest that bacteria or their slowly degradable components may initiate and sustain chronic inflammation and lead to islet amyloid deposits in type 2 diabetes. They also indicate that the classical complement pathway is activated in type 2 diabetes. Further investigations will be necessary and are important as they may open new avenues for the prevention of this age related chronic disorder. So far, approaches to treatment of 
type 2 diabetes have largely been directed at limiting the demand for insulin, it may be possible to devise methods for protecting the islet cells themselves, by reducing inflammation and preventing infection.

\section{ACKNOWLEDGEMENTS}

This work was funded by grants from the Société Académique Vaudoise, Fondation Fern Moffat, Switzerland (JM) and by the Pacific Alzheimer Research Foundation, Vancouver, Canada (PLM, JM) and by support of The Institute of Physiology and Embryology, University of Fribourg, Switzerland (JM). We would like to thank Pushpa Darekar and $\mathrm{Yu}$ Sheng for their help and contribution to the present study.

\section{REFERENCES}

[1] Cooper GJ, Willis AC, Reid KB, et al. Diabetes-associated peptide. Lancet 1987; 8565: 966.

[2] Sanke T, Bell GI, Sample C, Rubenstein AH, Steiner DF. An islet amyloid peptide is derived from an 89-amino acid precursor by proteolytic processing. J Biol Chem 1988; 263: 17243-6.

[3] Clark A, Nilsson MR. Islet amyloid: a complication of islet dysfunction or an aetiological factor in Type 2 diabetes? Diabetologia 2004; 47: 157-69.

[4] Cooper GJ, Leighton B, Dimitriadis GD, et al. Amylin found in amyloid deposits in human type 2 diabetes mellitus may be a hormone that regulates glycogen metabolism in skeletal muscle. Proc Natl Acad Sci USA 1988; 85: 7763-66.

[5] Fenesy KE. Periodontal disease: an overview for physicians. Mt Sinai J Med 1998; 65: 362-69.

[6] Grossi SG, Genco RJ. Periodontal disease and diabetes mellitus: a two-way relationship. Ann Periodontol 1998; 3: 51-61.

[7] Pihlstrom BL, Michalowicz BS, Johnson NW. Periodontal diseases. Lancet 2005; 366: 1809-20.

[8] Taylor GW. Bidirectional interrelationships between diabetes and periodontal diseases: an epidemiologic perspective. Ann Periodontol $2001 ; 6: 99-112$.

[9] Grossi SG, Skrepcinski FB, DeCaro T, et al. Treatment of periodontal disease in diabetics reduces glycated hemoglobin. J Periodontol 1997; 68: 713-19.

[10] Fox A. Role of bacterial debris in inflammatory diseases of the joint and eye. APMIS 1990; 98: 957-68.

[11] Picken MM. The changing concepts of amyloid. Arch Pathol Lab Med 2001; 125: 38-43.

[12] Toplak H, Haller EM, Lauermann T, et al. Increased prevalence of IgA-Chlamydia antibodies in NIDDM patients. Diabetes Res Clin Pract 1996; 32: 97-101.

[13] Kozak R, Juhasz E, Horvat G, et al. Helicobacter pylori infection in diabetic patients. Orv Hetil 1999; 140: 993-95.

[14] Quatrini M, Boarino V, Ghidoni A, Baldassarri AR, Bianchi PA, Bardella MT. Helicobacter pylori prevalence in patients with diabetes and its relationship to dyspeptic symptoms. J Clin Gastroenterol 2001; 32: 215-17.

[15] Gulcelik NE, Kaya E, Demirbas B, et al. Helicobacter pylori prevalence in diabetic patients and its relationship with dyspepsia and autonomic neuropathy. J Endocrinol Invest 2005; 28: 214-17.

[16] Hughes MK, Fusillo MH, Roberson BS. Positive fluorescent treponemal antibody reactions in diabetes. Appl Microbiol 1970; 19: 425-28.

[17] McGeer EG, Klegeris A, McGeer PL. Inflammation, the complement system and the diseases of aging. Neurobiol Aging 2005; 26(Suppl 1): S94-97.

[18] Guo JP, Petric M, Campbell W, McGeer PL. SARS corona virus peptides recognized by antibodies in the sera of convalescent cases. Virology 2004; 324: 251-56.

[19] Miklossy J, Darekar P, Gern L, Janzer RC, Bosman FT. Bacterial peptidoglycan in neuritic plaques in Alzheimer's disease. Alzheimers Res 1996; 2: 95-100.
[20] Puolakkainen M, Parker J, Kuo CC, Grayston JT, Campbell LA. Further characterization of Chlamydia pneumoniae specific monoclonal antibodies. Microbiol Immunol 1995; 39: 551-54.

[21] Meijer A, van Der Vliet JA, Roholl PJ, Gielis-Proper SK, de Vries A, Ossewaarde JM. Chlamydia pneumoniae in abdominal aortic aneurysms: abundance of membrane components in the absence of heat shock protein 60 and DNA. Arterioscler Thromb Vasc Biol 1999; 19: 2680-86.

[22] Andersen LP, Holck S, Povlsen CO. Campylobacter pylori detected by indirect immunohistochemical technique. APMIS 1988; 96: 55964.

[23] Andersen LP, Holck S. Possible evidence of invasiveness of Helicobacter (Campylobacter) pylori. Eur J Clin Microbiol Infect Dis 1990; 9: 135-38.

[24] Jonkers D, Stobberingh E, de Bruine A, Arends JW, Stockbrügger R. Evaluation of immunohistochemistry for the detection of Helicobacter pylori in gastric mucosal biopsies. J Infect 1997; 35: 14954.

[25] Miklossy J, Arai T, Guo JP, et al. LRRK2 expression in normal and pathologic human brain and in human cell lines. J Neuropathol Exp Neurol 2006; 65: 953-63.

[26] Biessels GJ, Staekenborg S, Brunner E, Brayne C, Scheltens P. Risk of dementia in diabetes mellitus: a systematic review. Lancet Neurol 2006; 5: 64-74.

[27] J Rogers, S Webster, LF Lue, et al. Inflammation and Alzheimer's disease pathogenesis. Neurobiol Aging 1996; 17: 681-86.

[28] McGeer EG, McGeer PL. Innate immunity in Alzheimer's disease: a model for local inflammatory reactions. Mol Interv 2001; 1: 2229.

[29] McGeer PL, McGeer EG. Local neuroinflammation and the progression of Alzheimer's disease. J Neurovirol 2002; 8: 529-38.

[30] Olsson S, Sundler R. The role of lipid rafts in LPS-induced signaling in a macrophage cell line. Mol Immunol 2006; 43: 607-12.

[31] Hintao J, Teanpaisan R, Chongsuvivatwong V, et al. The microbiological profiles of saliva, supragingival and subgingival plaque and dental caries in adults with and without type 2 diabetes mellitus. Oral Microbiol Immunol 2007; 22: 175-81.

[32] Patel P, Mendall MA, Carrington D, et al. North field TC: Association of $H$. pylori and Chlamydia pneumonia infections with coronary heart disease and cardiovascular risk factors. BMJ 1995; 311 : 711-14.

[33] Laitinen K, Laurila A, Pyhälä L, Leinonen M, Saikku P. Chlamydia pneumonia infection induces inflammatory changes in the aortas of rabbits. Infect Immun 1997; 65: 4832-35.

[34] Saikku P. Epidemiology of Chlamydia pneumoniae in atherosclerosis. Am Heart J 1999; 138(Suppl 5): S500-3.

[35] Leinonen M, Saikku P. Infections and atherosclerosis. Scand Cardiovasc J 2000; 34: 12-20.

[36] Mendall M, Goggin P, Levy J, Molineaux N, Strachan D, Camm A. Relation of Helicobacter pylori infection and coronary heart disease. Br Heart J 1994; 71: 437- 39.

[37] Glynn J. Helicobacter pylori and the heart. Lancet 1991; 334: 14346.

[38] Martin de Argila C, Boixeda D, Cantón R, Gisbert JP, Fuertes A. High seroprevalence of Helicobacter pylori infection in coronary heart disease. Lancet 1995; 346: 310.

[39] Renvert S, Pettersson T, Ohlsson O, Persson GR. Bacterial profile and burden of periodontal infection in subjects with a diagnosis of acute coronary syndrome. J Periodontol 2006; 77: 1110-19.

[40] Zaremba M, Gorska R, Suwalski P, Kowalski J. Evaluation of the incidence of periodontitis-associated bacteria in the atherosclerotic plaque of coronary blood vessels. J Periodontol 2007; 78: 322-27.

[41] De Luis DA, Garcia Avello A, Lasuncion MA, et al. Improvement in lipid and haemostasis patterns after Helicobacter pylori infection eradication in type 1 diabetic patients. Clin Nutr 1999; 18: 227-31.

[42] Abel L, Sanchez FO, J Oberti, et al. Susceptibility to leprosy is linked to the human NRAMP1 gene. J Infect Dis 1998; 177: 13345.

[43] Shaw MA, Donaldson IJ, Collins A, et al. Association and linkage of leprosy phenotypes with HLA class II and tumor necrosis factor genes. Genes Immun 2001; 2: 196-204. 
[44] McGeer PL, Itagaki S, Tago H, McGeer EG. Reactive microglia in patients with senile dementia of the Alzheimer type are positive for the histocompatibility glycoprotein HLA-DR. Neurosci Lett 1987; 79: $195-200$.

[45] Rogers J, Luber- J Narod, Styren SD, Civin WH. Expression of immune system-associated antigens by cells of the human central nervous system: relationship to the pathology of Alzheimer's disease. Neurobiol Aging 1988; 9: 339-49.
[46]

Griffin WS, Stanley LC, Ling C, et al. Brain interleukin 1 and S100 immunoreactivity are elevated in Down syndrome and Alzheimer disease. Proc Natl Acad Sci USA 1989; 86: 7611-15.

[47] McGeer PL, Akiyama H, Itagaki S, McGeer EG. Activation of the classical complement pathway in brain tissue of Alzheimer patients. Neurosci Lett 1989; 107: 341-46.

(C) Miklossy et al.; Licensee Bentham Open.

This is an open access article licensed under the terms of the Creative Commons Attribution Non-Commercial License (http://creativecommons.org/licenses/by$\mathrm{nc} / 3.0 /$ ) which permits unrestricted, non-commercial use, distribution and reproduction in any medium, provided the work is properly cited. 